\title{
Analyzing Bongaarts model and its applications in the context of Bangladesh
}

\author{
Tanha Mahjabeen $^{\mathrm{a}}$ and Imran Amit Khan ${ }^{\mathrm{b}}$ \\ ${ }^{a}$ Curtin University, Australia ${ }^{b}$ University of Dhaka, Bangladesh \\ onlytanha18@yahoo.com
}

\begin{abstract}
Achieving appropriate fertility rate is important for any country. In spite of having a higher fertility rate than desired Bangladesh has been able to reduce it in a remarkable extent in the recent years. This decline in fertility has created much interest among researchers, policy makers and academics because such dramatic change in fertility has occurred in Bangladesh without a substantial improvement in the socioeconomic status, health conditions and other factors which are usually required for fertility decline.
\end{abstract}

This paper provides a critical review of the principal proximate determinants of fertility and their fertility inhibiting effects using the 2007 (Bangladesh Demographic Health Survey) BDHS data. The analysis has been done following the Bongaarts framework for proximate determinants of fertility.

The analysis shows that contraception appears as the most prominent determinant in fertility reduction in Bangladesh, followed by marriage, lactational infecundability and induced abortion. The analysis reveals that although the fertility reducing effect of the marriage variable is increasing, its effect is offset by the declining trend in lactational amenorrhoea period. A review of these two variables suggests that their effect cannot be raised much due to the socio-economic and cultural reasons prevailing in the country. Thus the use of contraception will be the dominant factor for further reduction in fertility. The national goal of attaining a replacement level of fertility could be expected to be achieved if the rate of contraception use can be increased up to a certain level. The study also shows that Bangladesh is in the third phase of transition of proximate determinants of fertility and is moving quickly towards the fourth or final phase.

The findings of the study demonstrate that the policy implications that can be drawn in order to achieve further fertility decline are: campaigning for further increase in the age at marriage of women, especially in rural areas, encouraging efforts to increase the quality of contraceptive use to induce higher use-effectiveness that will lead to greater contribution to fertility decline, efforts should be made to increase the use of sterilization for those who have reached their desired fertility and want to limit further births; and providing more information to women about the cost and benefits of a longer duration of breastfeeding and use of colostrums.

Keywords: Fertility, Contraception, Proximate determinants, Population, Indices. 


\section{INTRODUCTION}

Bangladesh, along with other obstructions to socio-economic development, is burnt with a high fertility rate. It is one of the most populated countries in the world: 920 persons live per square kilometer, with 150 million people living in the country's small area of 147,570 square kilometers. It has a growth rate of 1.48 percent per year. Recently, a decline in fertility rate is noticed. Despite the recent decline from 6.3 in 1975 to 2.7 in 2007 (Mitra et al. 2007), the fertility rate is still far above the replacement level. The recent decline in fertility has created much interest among researchers, policy makers and academics because such a dramatic change in fertility has occurred in Bangladesh without a substantial improvement in the socio-economic status, health conditions and other factors which are usually required for fertility decline (Amin et al. 1993).

Fertility has a great impact on the socio-economic condition of a country. Understanding the level, pattern, and nature of fertility could help decision makers to make policy. The first systematic classification of the proximate determinants of fertility was made by Davis and Blake (1956). Proximate determinants of fertility are defined as the biological and behavioral factors through which social, economic and environmental variables affect fertility. Davis and Blake heralded the demographic literature for having made explicit the distinction between the factors, which directly and indirectly influence fertility. They identified direct factors, which are known as intermediate fertility variables as they mediate between fertility and other variables.

Later, in the late seventies Bongaarts (1978) revised Davis and Blake's framework and proposed a new system that incorporates only seven variables which he termed the "proximate determinants of fertility". Using data from 41 developed and developing countries Bongaarts and Potter (1983) observed that 96\% of the variation in the total fertility rates could be explained by four principal proximate determinants. The remaining three variables explain very little variation of the total fertility rate. Because of this result, it seemed reasonable to ignore these 'redundant' intermediate variables from subsequent analysis. To quantify the fertility inhibiting effect of the four major proximate determinants, Bongaarts developed a model, which is now widely used in fertility analysis.

This paper utilizes the data extracted from the Bangladesh Demographic and Health Survey 2007, a nationally representative survey of 10996 ever-married women of age 10-49, which was conducted under the authority of the National Institute of Population Research and Training (NIPORT) of the Ministry of Health and Family Welfare. Data on abortion of Matlab study (ICDDR,B 1996) is used as a proxy as these data are not reliable. The main objective of this paper is to analyze the proximate determinants of fertility in Bangladesh and to estimate their fertility inhibiting effects.

\section{THE STRUCTURE OF BONGAARTS MODEL}

The Bongaarts model summarizes the relationship between the total fertility rate and the proximate determinants of fertility, and is worldwide known as the Bongaarts model of proximate determinants. The Bongaarts model assumes that the natural reproductive capacity, i.e. total fecundity rate (TF) of women is nearly the same for all women, but their actual reproductive performance is modified by four major proximate determinants. The fertility effects of the four most important proximate determinants, marriage, contraception, induced abortion and postpartum infecundability are measured by four indices $C_{m}, C_{c}, C_{a}$ and $\mathrm{C}_{\mathrm{i}}$ respectively. The Bongaarts model is as follows:

\begin{tabular}{|c|c|}
\hline & $\mathrm{Cm}_{\mathrm{m}}$ \\
\hline $\begin{array}{l}\text { Where, } \\
\mathrm{C}_{\mathrm{m}}=\end{array}$ & $\begin{array}{l}\text { index of marriage }\left(\mathrm{C}_{\mathrm{m}} \text { ranges from } 0 \text { to } 1 ; \text { equals } 1 \text { if all women of }\right. \\
\text { reproductive age are married and } 0 \text { in the absence of marriage })\end{array}$ \\
\hline$C_{c}=$ & $\begin{array}{l}\text { index of contraception }\left(\mathrm{C}_{\mathrm{c}} \text { ranges from } 0 \text { to } 1 \text {; equals } 1 \text { in the absence of contraception and } 0 \text { if all }\right. \\
\text { fecund women use } 100 \text { percent effective contraception) }\end{array}$ \\
\hline $\mathrm{C}_{\mathrm{a}}=$ & $\begin{array}{l}\text { index of induced abortion }\left(\mathrm{C}_{\mathrm{a}} \text { ranges from } 0 \text { to } 1 \text {; equals } 1 \text { in the absence of induced abortion and }\right. \\
0 \text { if all pregnancies are aborted) }\end{array}$ \\
\hline$C_{i}=$ & $\begin{array}{l}\text { index of postpartum infecundability }\left(\mathrm{C}_{\mathrm{i}} \text { ranges from } 0 \text { to } 1 \text {; equals } 1 \text { in the absence of lactation }\right. \\
\text { and postpartum abstinence and } 0 \text { if the duration of infecundability is infinite) }\end{array}$ \\
\hline
\end{tabular}

The TF values of most populations fall within the range of 13 to 17 births per woman, with an average of 15.3 (Bongaarts 1982). Bongaarts expressed his model as:

$$
\mathrm{TFR}=\mathrm{C}_{\mathrm{m}} \times \mathrm{C}_{\mathrm{c}} \times \mathrm{C}_{\mathrm{a}} \times \mathrm{C}_{\mathrm{i}} \times 15.3
$$




\subsection{Estimation of the Indices}

There are different ways to estimate the indices $C_{m}, C_{c}, C_{a}$ and $C_{i}$. However, in most applications the indices are estimated directly from the measures of the proximate determinants and are described as follows:

\section{Estimation of $\mathbf{C}_{\mathbf{m}}$}

The index of marriage is determined by the age- specific proportions of currently married among females. The index $C_{m}$ is not simply equal to the proportion of all women of reproductive age that is married because the fertility impact of marriage also depends on the age distribution of married women. Married women in the central childbearing years contribute more to the TFR than the youngest or oldest women because the age-specific marital fertility rates reach their maximum in the central childbearing ages. To take this age effect into account, the index $C_{m}$ is estimated as the weighted average of the age-specific proportions of females currently married, with weights provided by the age-specific marital fertility rates:

Where

$$
\mathrm{C}_{\mathrm{m}}=\frac{\sum \mathrm{m}(\mathrm{a}) \mathrm{g}(\mathrm{a})}{\sum \mathrm{g}(\mathrm{a})}
$$

$\mathrm{m}(\mathrm{a})=$ the age-specific proportions of currently married (or in consensual union) among females $\mathrm{g}(\mathrm{a})=$ the age-specific marital fertility rates

\section{Estimation of $\mathbf{C}_{\mathbf{c}}$}

The index of contraception varies inversely with prevalence and use-effectiveness of contraception practiced by couples in the reproductive age groups. The index $\mathrm{C}_{\mathrm{c}}$ is estimated as:

Where

$$
\mathrm{C}_{\mathrm{c}}=1-1.08 \times \mathrm{u} \times \mathrm{e}
$$

$\mathrm{u}=\quad$ the proportion currently using contraception among married women of reproductive age (male methods, abstinence other than postpartum, and sterilizing operations are included)

$\mathrm{e}=\quad$ the average use-effectiveness of contraception

$1.08=$ the adjustment factor for sterilizing, on an assumption that all the contraceptive users may not be fecund at the time of using contraceptives and a small proportion of sterile women may use contraceptive without knowing their fecundity.

\section{Estimation of $\mathbf{C}_{\mathbf{i}}$}

If no breastfeeding and postpartum abstinence are practiced, the birth interval averages about 20 months, the sum of 1.5 months of minimum postpartum an ovulation, 7.5 months of waiting time to conception, 2 months of time added by spontaneous intrauterine mortality, and 9 months for a full term pregnancy. In the presence of breastfeeding and postpartum abstinence the average birth interval equals, approximately 18.5 months $(7.5+9+2)$ plus the duration of postpartum infecundability. Then index $\mathrm{Ci}$ is estimated as:

where

$$
\mathrm{C}_{\mathrm{i}}=\frac{20}{18.5+\mathrm{i}}
$$

$\mathrm{i}=$ the average duration of postpartum infecundability caused by breastfeeding or postpartum abstinence.

\section{Estimation of $\mathbf{C}_{\mathbf{a}}$}

As suggested by Bongaarts and Potter (1985), the index of induced abortion, $\mathrm{C}_{\mathrm{a}}$ can be estimated as follows:

$$
\begin{aligned}
\mathrm{C}_{\mathrm{a}} & =\frac{\mathrm{TFR}}{\mathrm{TFR}+\mathrm{b} \times \mathrm{TA}} \\
& =\frac{\mathrm{TFR}}{\mathrm{TFR}+0.4 \times(1+\mathrm{u}) \times \mathrm{TA}}
\end{aligned}
$$

where

$\mathrm{TA}=$ total abortion rate

$\mathrm{B}=0.4 \times(1+\mathrm{u})$ is the average number of births averted per induced abortion

$\mathrm{u}=$ the proportion of women of reproductive age currently using contraception

The complement of each index represents the proportionate reduction in fertility attributable to each fertility determinant. The lower the index value the greater is the fertility reducing impact. The index $\mathrm{C}_{\mathrm{m}}$ represents the proportion by which TFR is smaller than TMFR as a result of the marital pattern. Similarly, the index $\mathrm{C}_{c}$ gives the proportion by which TMFR is smaller than TN with the level and effectiveness of contraceptive use, the index $\mathrm{C}_{\mathrm{i}}$ gives by how much $\mathrm{TN}$ is smaller than $\mathrm{TF}$ due to the effect of lactational infecundability. 


\section{FERTILITY INHIBITING EFFECTS OF THE PROXIMATE DETERMINANTS}

To estimate the fertility inhibiting effects of the four principal proximate determinants: marriage, contraception, induced abortion and lactational infecundability, the formulae of (2.1), (2.2), (2.3) and (2.4) as discussed in the previous section are applied. The summary measures, which are needed for the application of the model, are presented in table 3.1. In the table, total marital fertility rate (TMFR) is calculated by summing up Age-Specific Marital Fertility Rate (ASMFR) for each age group in the five year bracket and then, multiplying the derived sum by 5 . The ASMFR have been derived by dividing the age-specific fertility rates by the proportion of women currently married in each age group. The estimates of the indices of the four major proximate determinants for Bangladesh are presented in table 3.2 and that for the different background characteristics are presented in table 3.3. The complement of each index represents the proportionate reduction in fertility attributable to each fertility determinant.

Table 3.1. Estimates of selected reproductive measures from BDHS 2007

\begin{tabular}{||l||c||}
\hline \hline Reproductive measures & Value \\
\hline \hline Total Fertility Rate (TFR) & 2.700 \\
Total Marital Fertility Rate (TMFR) & 4.200 \\
Proportion of Contraceptive Use (u) & 0.581 \\
Contraceptive Use-effectiveness (e) & 0.880 \\
Average Duration of Postpartum Amenorrhoea (i) & 5.800 \\
Total Abortion Rate (TA) & 0.180 \\
\hline
\end{tabular}

Table 3.2. Estimated indices for the four major proximate determinants of fertility and their impacts for Bangladesh, 2007

\begin{tabular}{|c|c|c|}
\hline Indices of proximate determinants of & Estimated value & Impact on fertility reduction \\
\hline Index of marriage $\left(\mathrm{C}_{\mathrm{m}}\right)$ & 0.750 & $25.0 \%$ \\
\hline Index of contraception $\left(\mathrm{C}_{\mathrm{c}}\right)$ & 0.489 & $51.1 \%$ \\
\hline Index of induced abortion $\left(\mathrm{C}_{\mathrm{a}}\right)$ & 0.959 & $4.0 \%$ \\
\hline Index of lactational infecundability $\left(\mathrm{C}_{\mathrm{i}}\right)$ & 0.823 & $17.7 \%$ \\
\hline
\end{tabular}

Table 3.3. Estimated indices for the four principal proximate determinants by selected background characteristics

\begin{tabular}{||l|l|l|l|l||}
\hline \hline $\begin{array}{l}\text { Background } \\
\text { characteristics }\end{array}$ & $\begin{array}{l}\text { Index of } \\
\text { marriage }\left(\mathbf{C}_{\mathbf{m}}\right)\end{array}$ & $\begin{array}{l}\text { Index of } \\
\text { contraception }\left(\mathbf{C}_{\mathbf{c}}\right)\end{array}$ & $\begin{array}{l}\text { Index of } \\
\text { abortion }\left(\mathbf{C}_{\mathbf{a}}{ }^{*}\right)\end{array}$ & $\begin{array}{l}\text { Index of } \\
\text { amenorrhoea }\left(\mathbf{C}_{\mathbf{i}}\right)\end{array}$ \\
\hline \hline Residence & & & & \\
Urban & 0.619 & 0.411 & 1.000 & 0.844 \\
Rural & 0.750 & 0.487 & 1.000 & 0.820 \\
\hline Division & 0.642 & 0.465 & 1.000 & \\
Barisal & 0.802 & 0.583 & 1.000 & 0.813 \\
Chittagong & 0.687 & 0.464 & 1.000 & 0.826 \\
Dhaka & 0.733 & 0.400 & 1.000 & 0.899 \\
Khulna & 0.822 & 0.377 & 1.000 & 0.764 \\
Rajshahi & 0.653 & 0.701 & 1.000 & 0.723 \\
Sylhet & & 0.519 & 1.000 & \\
\hline Education & 0.886 & 0.453 & 1.000 & 0.704 \\
No education & 0.484 & 1.000 & 0.778 \\
Primary incomplete & 0.846 & 0.427 & 1.000 & 0.806 \\
Primary complete & 0.640 & & 1.000 & 0.873 \\
Secondary+ & 0.561 & 0.479 & 1.000 & 0.699 \\
\hline Wealth & 0.486 & 1.000 & 0.826 \\
Lowest & 0.431 & 0.889 \\
Middle & 0.685 & 0.590 & Highest
\end{tabular}

*Due to unavailability of data the index of induced abortion could not be estimated and assumed as 1.000 indicating no impact of induced abortion

The results indicate that in 2007, contraception has the highest fertility reducing effect, accounting for 51.1 percent $(\mathrm{Cc}=0.489)$ reduction of TN relative to TMFR, for entire Bangladesh, compared to 45.5 percent in 
2004.The corresponding figures for rural and urban areas are 51.3 and 58.9 percent respectively. The percentage reduction in fertility due to contraception is also significant for the various levels of education and divisions. The fertility reducing effect of contraception is the highest in Rajshahi division and lowest in Sylhet division. Among the different education levels contraception plays the most remarkable role in fertility decline. The percent reduction in fertility due to contraception is the highest in wealthiest group.

Marriage is the second most important fertility-reducing factor, which reduces the actual fertility level below the marital fertility by 25 percent $\left(\mathrm{C}_{\mathrm{m}}=0.75\right)$. The corresponding figures for rural and urban areas are 25 and 30.9 percent respectively. The same percentage observed among illiterate women is lower than the corresponding figure for any other educational subgroup. Among the divisions the highest reduction in fertility due to marriage is observed in Barishal and the lowest in Rajshahi. Marriage leaves the least effect on fertility in the lower wealth group.

Lactational infecundability is the third most important fertility-reducing factor, reducing the total fecundity rate by 17.7 percent $\left(C_{i}=0.823\right)$. The corresponding figures for rural and urban areas are 18 and 15.4 percent respectively. In the illiterate group of women the percentage reduction in fertility due to lactational infecundability is greater than that of any other educational group. We see very significant differences in the three wealth groups for the effect in fertility due to lactational infecundability. In Bangladesh induced abortion has the least impact on fertility. In 2007 , induced abortion reduced 4.1 percent $\left(\mathrm{C}_{\mathrm{a}}=0.959\right)$ fertility in Bangladesh, compared to 3.7 percent in 2004.

\subsection{The Transition in the Proximate Determinants of Fertility}

As a population moves through the transition from natural to controlled fertility there is, by definition, an increase in deliberate marital fertility control. To provide a clear picture of the trends in the proximate determinants, Bongaarts (1982) showed four transition phases according to the level of fertility based on the data of 41 developed and developing countries-

Phase I: TFR $>6.0$

Phase II: $4.5 \leq$ TFR $\leq 6.0$

Phase III: $3.0 \leq$ TFR $\leq 4.5$

Phase IV: TFR $<3.0$

Bongaarts showed that the fertility of most populations in phase I is close to natural while populations in phase IV have completed most or all of the fertility transition. Estimates of the proximate determinants--the indices $C_{m}, C_{c}, C_{a}$ and $C_{i}$ and the total marital fertility rate, total fertility rate and other selected reproductive measures are presented in table 3.4 for the years 1975, 1989, 1993-94, 1996-97, 2004 and 2007.

Table 3.4. Estimates of selected reproductive measures and derived indices of proximate determinants

\begin{tabular}{|l||l||l||l||l|l||l||}
\hline $\begin{array}{l}\text { Reproductive measures and model } \\
\text { indices }\end{array}$ & $\begin{array}{l}\mathbf{1 9 7 5} \\
\text { BFS }\end{array}$ & $\begin{array}{l}\mathbf{1 9 8 9} \\
\text { BFS }\end{array}$ & $\begin{array}{l}\mathbf{1 9 9 3 - 9 4} \\
\text { BDHS }\end{array}$ & $\begin{array}{l}\text { 1996-97 } \\
\text { BDHS }\end{array}$ & $\begin{array}{l}\mathbf{2 0 0 4} \\
\text { BDHS }\end{array}$ & $\begin{array}{l}\mathbf{2 0 0 7} \\
\text { BDHS }\end{array}$ \\
\hline \hline Prevalence of contraceptive use & 0.080 & 0.310 & 0.450 & 0.490 & 0.581 & .558 \\
\hline \hline Use-effectiveness of contraception & 0.760 & 0.820 & 0.810 & 0.810 & 0.870 & .880 \\
\hline Total induced abortion rate & - & 0.180 & 0.180 & 0.180 & 0.180 & .180 \\
\hline \hline Duration of postpartum amenorrhoea & 14.600 & 11.520 & 12.110 & 10.800 & 6.100 & 5.80 \\
\hline Index of marriage & 0.867 & 0.850 & 0.801 & 0.761 & 0.743 & 0.750 \\
\hline \hline Index of contraception & 0.937 & 0.727 & 0.610 & 0.570 & 0.454 & .489 \\
\hline \hline Index of induced abortion & 1.000 & 0.982 & 0.971 & 0.968 & 0.963 & .959 \\
\hline \hline Index of postpartum infecundability & 0.604 & 0.666 & 0.653 & 0.683 & 0.813 & .823 \\
\hline \hline Total fertility rate & 6.330 & 5.120 & 3.440 & 3.270 & 3.000 & 2.7 \\
\hline \hline Total marital fertility rate & 7.420 & 6.390 & 4.520 & 4.410 & 4.000 & 4.2 \\
\hline
\end{tabular}

According to Bangladesh Fertility Survey (BFS) TFR was 6.33 in 1975 in Bangladesh (Islam \& Islam 1993), which was close to natural fertility. These results indicate that Bangladesh was in the first phase of fertility transition according to Bongaarts's classification during 1970s. In 1989 TFR declined to 5.12 from 6.33 in 1975 indicating that Bangladesh was in the second phase of fertility transition according to Bongaarts classification (Islam \& Islam 1993). The TFR of Bangladesh again declined from 5.12 to 3.44 in 1993-94 (Islam et al. 1998). According to Bongaarts's classification Bangladesh was in the third phase of fertility transition in 1996-97 (Mitra et al. 1996-97). Bangladesh was in the last step of the third phase of fertility transition in 2004 (Mitra et al. 2004). Although Bangladesh was still in Phase III, the trends in the various fertility measures and estimates of the indices of proximate determinants show that the country is knocking at 
the door of the fourth phase of the fertility transition.

As expected from the previous survey, it is found from the BDHS 2007 that Bangladesh has become successful in reaching the final level of fertility rate which is 2.7 . One thing must be added that though Bangladesh is in the final stage of fertility rate presently, it is still lagging far behind in attaining the replacement level of 2.1 children per woman (Mitra et al. 2007). However, analyzing the past trends, it could be hoped that if effective measures and realistic strategies are adopted, it would not take very long to reach the cherished level.

\section{PROJECTION OF FUTURE FERTILITY}

The Bongaarts model of proximate determinants is now used worldwide for fertility analysis. Moreover it can be used for projecting future fertility and estimating the required contraceptive prevalence rate to reach a certain fertility level. This is illustrated below.

Suppose that $\mathrm{TFR}_{1}$ and $\mathrm{TFR}_{2}$ be the total fertility rates, in respectively, year1 (the present) and year2 (a year in the future), and let the corresponding levels of contraceptive prevalence and use-effectiveness be $\mathrm{u}_{1}$ and $\mathrm{e}_{1}$, and $\mathrm{u}_{2}$ and $\mathrm{e}_{2}$, respectively. The objective now is to estimate the level of the total fertility rate if contraceptive practice changes between year 1 and year 2. Here we assume that the indices for all other proximate determinants except for contraception remain constant, i.e., $\mathrm{C}_{\mathrm{m} 1}=\mathrm{C}_{\mathrm{m} 2}, \mathrm{C}_{\mathrm{a} 1}=\mathrm{C}_{\mathrm{a} 2}, \mathrm{C}_{\mathrm{i} 1}=\mathrm{C}_{\mathrm{i} 2}, \mathrm{TF}_{1}=\mathrm{TF}_{2}$. Then obviously-

$$
\frac{T_{2 F R}}{\text { TFR }_{1}}=\frac{C_{c 2}}{C_{c 1}}
$$

Or, equivalently--

$$
\begin{aligned}
T F R_{2}= & \frac{C_{c 2}}{C_{c 1}} \times T F R_{1} \\
& =\frac{\left(1-1.08 \times u_{2} \times e_{2}\right)}{\left(1-1.08 \times u_{1} \times e_{1}\right)} \times T F R_{1}
\end{aligned}
$$

With the help of this equation we can project fertility in some future time. Suppose that the government of Bangladesh wants to increase the contraceptive prevalence rate to reduce the level of fertility. In Bangladesh the current contraceptive prevalence rate is 55.8 percent. Let assume that the government has taken a program to increase contraceptive prevalence rate and the program increases the current contraceptive prevalence rate to 65.0 percent. If this achieved prevalence rate remains constant till the year 2020, then we can project the TFR for the year 2020. Then the projected total fertility becomes-

$$
\begin{aligned}
\operatorname{TFR}_{2010} & =\frac{\left(1-1.08 \times u_{2020} \times e_{2020}\right)}{\left(1-1.08 \times u_{2007} \times e_{2007}\right)} \times T_{F R} 2007 \\
& =\frac{(1-1.08 \times 0.65 \times 0.87)}{(1-1.08 \times 0.558 \times 0.87)} \times 2.7 \\
& =2.19
\end{aligned}
$$

Here $e_{2020}$ and $e_{2007}$ are contraceptive use-effectiveness for the year 2020 and 2007 and it is assumed that contraceptive use-effectiveness remains constant.

\section{Projection of Contraceptive Prevalence Rate Required to Reach Replacement level}

Suppose that the government of Bangladesh wants to achieve replacement level fertility by the year 2020 . For this purpose the government may want to increase the current contraceptive prevalence rate to achieve that goal. In this case the government may be willing to allocate an exact amount of money to enhance the family planning program, if the required contraceptive prevalence rate is known. The Bongaarts model can help the government to project the contraceptive prevalence rate required to reach the replacement level. A little rearrangement of the equation (4.1) leads to the following equation, which can be used to estimate the contraceptive prevalence rate required to achieve a projected fertility level:

$$
u_{2}=\frac{1}{1.08 \times e_{2}} \times\left[1-\frac{T F R_{2}}{T F R_{1}} \times C_{c 1}\right]
$$


The total fertility rate in 2007 is 2.7 and expected TFR in the year 2020 is 2.2. Then using the relation (4.2), the required contraceptive prevalence rate to achieve replacement level fertility is given by-

$$
\begin{aligned}
u_{2010} & =\frac{1}{1.08 \times 0.88} \times\left(1-\frac{2.1 \times 0.489}{2.7}\right) \\
& =0.65
\end{aligned}
$$

Here 0.489 is the value of $\mathrm{C}_{\mathrm{c} 1}$ and 2.1 is the replacement fertility level.

\section{CONCLUSION AND RECOMMENDATIONS}

Fertility has a great impact on the socio-economic condition of a country. Understanding the level, pattern, and nature of fertility could help decision makers for policy formulation. From the descriptions and implications discussed above it is clear that the Bongaarts model could be a very well-organized and effective tool in this regard and consequently in controlling the massive population in Bangladesh. Realistic and achievable targets could also be set with its help while implementing policies into action to turn the population of the country into a resource from a problem. However from the data analyzed throughout the paper the following recommendations could be drawn:

- As the use of contraception plays the most important role in fertility reduction, information and campaigning on this issue should be re-emphasized.

- Awareness raising programs should be undertaken in order to prevent female child or adolescent marriage- especially among illiterate people and in the rural areas which will help to increase the age at marriage of women.

- Special programs should be implemented to encourage parents in breastfeeding in urban areas and among wealthy people as it seems that lack of interest rather than information is the main problem.

- Couples should be encouraged for sterilization after they achieved their desired fertility in order to avoid further unwanted pregnancy.

- Due to traditional socio-cultural background, open consultation about reproductive health issues are not encouraged in Bangladesh which causes lack of information. Education system and media can play important role in overcoming this problem.

\section{REFERENCES}

Amin, R.J., Chowdhury, A., Ahmed, U., Hill, R.B., and Kabir, M. (I993). Reproductive change in Bangladesh: Evidence from recent data. Asia-Pacific Population Journal. 8(4): 39-58.

Bongaarts, J. (1982). The fertility-inhibiting effects of the intermediate fertility variables. Studies in Family Planning. 13(6/7): 179-189.

Bongaarts, J. (1978). A framework for analyzing the proximate determinants of fertility. Population and Development Review. 4(1): 105-132.

Bongaarts, J., and Potter, R.G. (1983). Fertility, Biology and Behavior: An Analysis of The Proximate Determinants. Academic Press, New York.

Davis, K., and Blake, J. (1956). Social structure and fertility: An analytical framework. Economic Development and Cultural Change. 4(4): 211-235.

International Centre for Diarrhoeal Disease Research, Bangladesh (ICDDR,B) (1996). Fertility Intention and Subsequent Abortion in Matlab, Bangladesh. ICDDR,B, Dhaka.

Islam, M.M., Mamun, A.A., and Bairagi, R. (1998). The proximate determinants of fertility in Bangladesh: Evidence from BDHS 1993-94. Asia-Pacific Population Journal. 13: 3-22.

Islam, M.N., and Islam, M.M. (1993). Biological and behavioral determinants of fertility in Bangladesh: 1975-1989. Asia-Pacific Population Journal. 8(1): 3-18.

Mitra, S.N., Al-Sabir, A., Cross, A.R., and Jamil, K. (1997). Bangladesh Demographic and Health Survey (BDHS) 1996-97. NIPORT, Mitra and Associates, Dhaka.

Mitra, S.N., Al-Sabir, A., Cross, A., Islam, S., Kumar, S., and Bhadra, S.K. (2009). Bangladesh Demographic and Health Survey (BDHS) 2007. NIPORT, Dhaka.

Mitra, S.N., Al-Sabir, A., Cross, A., Islam, S., Kumar, S., and Bhadra, S.K. (2004). Bangladesh Demographic and Health Survey (BDHS) 2004. NIPORT, Mitra and Associates, Dhaka. 